\title{
Postgraduate Colloquium (2016)
}

The second edition of postgraduate (PG) Colloquium was held at Ragas Dental College and Hospital, Chennai, Tamil Nadu, India on September 23 and 24, 2016, on behalf of the Conservative Dentistry and Endodontics Association of Tamil Nadu, India. Drs Revathi Miglani, Sunnel Kumar Chinni, and Chitrarasan MD (Radiologist) gave guest lectures. Around 250 PG students and delegates across PG colleges of Tamil Nadu attended the 2-day event. The students presented papers and e-posters. Dr S Ramachandran, former Principal, Ragas Dental College and Hospital; Dr R Indira, Former HOD, Dept. of Conservative Dentistry and Endodontics, Ragas Dental College; Dr VG Sugumar, Former Principal and HOD, Sri Balaji Dental College and Hospital were honoured with the LIFE TIME achievement award. For the first time mixed handball game was conducted for the PG students. Government Dental College, Chennai, Tamil Nadu, India were the winners and students from Sri Ramachandra Dental College were the runner-up respectively. The event was attended by HODs and staff of various dental colleges across Chennai and Tamil Nadu. The editorial team of the Journal of Conservative Dentistry and Endodontics presented the second edition of the journal to all the invitees. The Association's President, Dr MR Srinivasan, Hon. Secretary; Dr M Rajasekaran, Guest of honour; Mr Kanakaraj, Chairman, Ragas Dental College and Hospital; Dr NS Azhagarasan, Principal Ragas Dental College and Hospital; Dr R Anil Kumar, HOD, Department of Conservative Dentistry and Endodontics, Ragas Dental College and Hospital, Chennai, Tamil Nadu, India, Dr. Karumaran, Prof, Scientific Committee Chairman, Ragas Dental College and Hospital, Chennai, Tamil Nadu, India, gave away the prizes for best papers and posters at the valedictory function.scientific meet
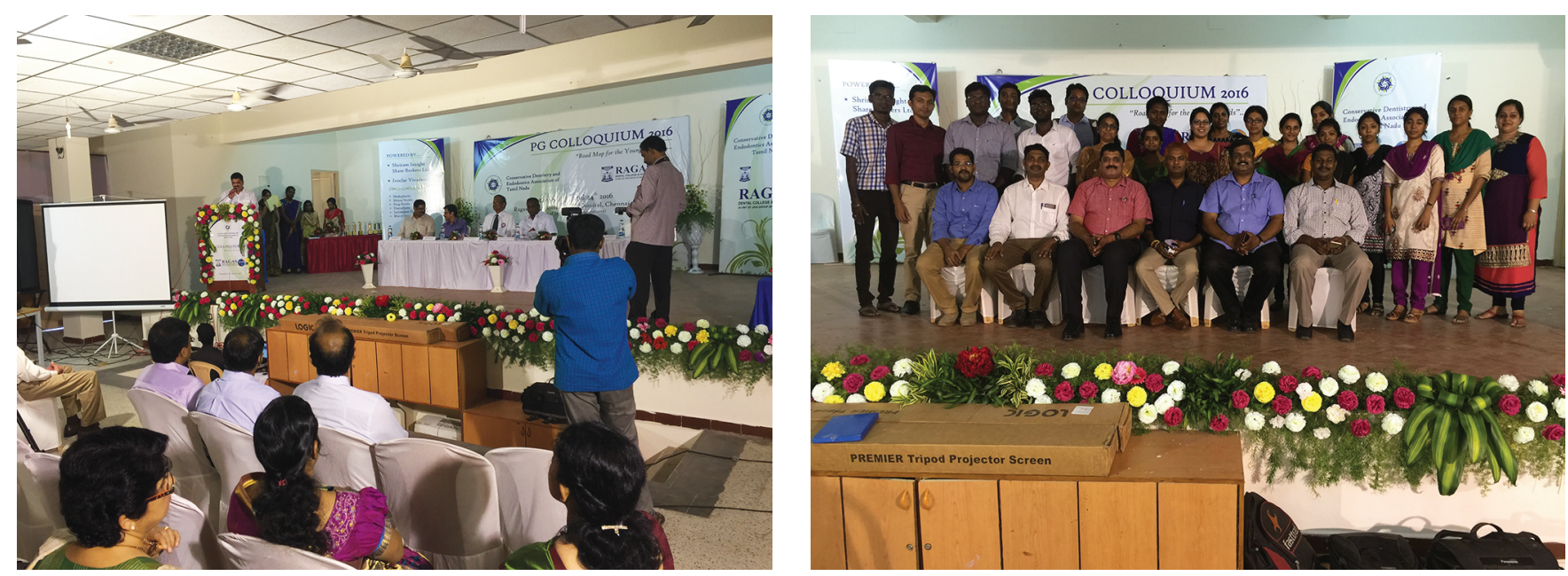

Meenakshisundaram Rajasekaran Professor

Ragas Dental College and Hospital, Chennai, Tamil Nadu, India

Veni Ashok Baskaran

Professor

Ragas Dental College and Hospital, Chennai, Tamil Nadu, India 
